\title{
Quality of Cardiopulmonary Resuscitation and 5-Year Survival Following in-Hospital Cardiac Arrest
}

Lone Due Vestergaard'

Kasper Glerup Lauridsen ${ }^{2,3}$

Niels Henrik Vinther

Krarup 4

Jane Uhrenholt Kristensen'

Lone Kaerslund Andersen'

Bo Løfgren (1D) $2,3,5$

'Department of Cardiology, Lillebaelt Hospital, Vejle, Denmark; ${ }^{2}$ Department of Internal Medicine, Randers Regional Hospital, Randers, Denmark; ${ }^{3}$ Research Center for Emergency Medicine, Aarhus University Hospital, Aarhus, Denmark;

${ }^{4}$ Cardiologist in Private Practice, Hjerteklinik Midt, Aarhus, Denmark; ${ }^{5}$ Department of Clinical Medicine, Aarhus University, Aarhus, Denmark
Correspondence: Lone Due Vestergaard Department of Cardiology, Lillebaelt Hospital, Beriderbakken 4, Vejle, 7I00, Denmark

Tel +45 25329737

Email Idue@hotmail.com
Purpose: To improve cardiac arrest survival, international resuscitation guidelines emphasize measuring the quality of cardiopulmonary resuscitation (CPR). We aimed to investigate CPR quality during in-hospital cardiac arrest (IHCA) and study long-term survival outcomes. Patients and Methods: This was a cohort study of IHCA from December 2011 until November 2014. Data were collected from the hospital switch board, patient records, and from defibrillators. Impedance data from defibrillators were analyzed manually at the level of single compressions. Long-term survival at 1-, 3-, and 5 years is reported.

Results: The study included 189 IHCAs; median (interquartile range (IQR)) time to first rhythm analysis was 116 (70-201) seconds and median (IQR) time to first defibrillation was 133 (82-264) seconds. Median (IQR) chest compression rate was 126 (119-131) per minute and chest compression fraction (CCF) was 78\% (69-86). Thirty-day survival was $25 \%$, while 1-year-, 3-year-, and 5-year survival were $21 \%, 14 \%$, and $13 \%$, respectively. There was no significant association between any survival outcomes and CCF, whereas chest compression rate was associated with survival to 30 days and 3 years. Overall, 5-year survival was associated with younger age (median 68 vs 74 years, $p=0.003$ ), less comorbidity (Charlson comorbidity index median 3 vs $5, p<0.001)$, and witnessed cardiac arrest $(96 \%$ vs $77 \%$, $p=0.03$ ).

Conclusion: We established a systematic collection of IHCA CPR quality data to measure and improve CPR quality and long-term survival outcomes. Median time to first rhythm check/defibrillation was $<3$ minutes, but median chest compression rate was too fast and median CCF slightly below $80 \%$. More than half of 30 -day survivors were still alive at 5 years.

Keywords: in-hospital cardiac arrest, transthoracic impedance, long-term survival, chest compression rate, chest compression fraction

\section{Introduction}

The incidence of in-hospital cardiac arrest (IHCA) is estimated to be 1-10 per 1,000 admissions, with a 30 -day survival rate of $15-42 \% .^{1-5}$ Variation between hospitals is considerable, with an implied potential for improvement. ${ }^{6,7}$

Studies have shown that cardiopulmonary resuscitation (CPR) with high-quality chest compressions and a high chest compression fraction (CCF) are associated with improved survival following out-of-hospital cardiac arrest. ${ }^{8-10}$ Meanwhile, data on chest compression quality and survival outcomes following in-hospital cardiac arrest is sparse and the existing studies are small. ${ }^{11-15}$ 
Performance debriefings after IHCA are associated with improved CPR quality and survival outcomes. ${ }^{16,17}$ International resuscitation guidelines therefore recommend the use of data-driven performance evaluation debriefings to improve survival outcomes. ${ }^{18-20}$ The guidelines also emphasize that healthcare systems with a responsibility for the management of patients in cardiac arrest should evaluate their cardiac arrest treatment to ensure the best achievable survival rates. However, our knowledge on survival outcomes following IHCA beyond 30 days is limited, and survival outcomes beyond 1 year are largely unknown. ${ }^{5,21-24}$

Transthoracic impedance (TTI) data from manual and automatic defibrillators may be used to evaluate CPR quality. A number of studies have investigated the use of TTI in out-of-hospital cardiac arrest (OHCA) and it has been shown to be an effective, accurate, and readily available tool to evaluate cardiopulmonary resuscitation (CPR) quality. ${ }^{25-27}$ In comparison, only a few studies have investigated the use of TTI in IHCA. ${ }^{13,28}$

The aim of this study was to investigate CPR quality during IHCA using TTI and to study long-term survival outcomes.

\section{Materials and Methods Study Setting: Hospital and Cardiac Arrest Organization}

This was a cohort study conducted at Lillebaelt Hospital, Vejle, a regional hospital in Denmark covering a catchment area of approximately 135,000 patients. ${ }^{29}$ In the study period, the number of admissions were between 19,000 and 22,000 annually.

Lillebaelt Hospital, Vejle, has an emergency department (ED), a Department of Orthopedic Surgery, a Department of Abdominal Surgery, and a Department of Internal Medicine. In addition, the hospital has a ninebed intensive care unit, and a cardiology department with a catheterization laboratory performing diagnostic coronary angiography and pacemaker implantations.

The hospital has a multidisciplinary cardiac arrest team who are summoned by phone through the hospital switchboard. The switchboard operator receiving the call activates the cardiac arrest team. The cardiac arrest team is led by either a senior cardiology fellow or an attending cardiologist from 08.00-21.00 and from $21.00-08.00$ by an internal medicine resident. In addition, the cardiac arrest team consists of an anesthesiology fellow, a nurse anesthetist, and two orderlies.
The orderlies bring a manual defibrillator (Lifepak 20, Physio-Control, Redmond, WA) to all cardiac arrests. With the aim of reducing time to first defibrillation, Automatic External Defibrillators (AEDs) (Lifepak CR Plus, PhysioControl) are distributed throughout the hospital in all wards, excluding the ED, intensive care unit, and cardiology department, which all use manual defibrillators (Lifepak 20, Physio-Control).

\section{Data Collection}

All cardiac arrests in the hospital in the study period from December 1, 2011 until November 30, 2014 were included. All patients arriving in the ED with ongoing CPR were excluded.

A study nurse contacted the hospital switchboard operators on a weekly basis to collect data on time of cardiac arrest calls, location of cardiac arrest, and the patient social security number. If the social security number was not available at the switchboard, the specific department in which IHCA occurred was contacted to obtain this information.

To ensure that all IHCAs had been identified, the Department of Anesthesiology was also contacted. Their independent registry of cardiac arrests (Danish Anesthesia Database $)^{30}$ was used to identify possible IHCAs not identified after contacting the switchboard. Finally, the Hospital Technical Service Department was contacted for information about AED use.

Data on patient demographics, comorbidities, immediate survival outcome, and cardiac arrest treatment were collected from patient records. Long-term outcomes, ie, 1-, 3-, and 5-year mortality, were collected until 2019 from the Danish Civil Registration System, which automatically transfers information on mortality to the patient records.

The following data was collected from defibrillators: Continuous rhythm data, time of first rhythm analysis/ defibrillation, episode duration, compression rate, and chest compression fraction (CCF).

Permission to collect data was obtained from the Danish Data Protection Agency case number 18/28817. According to Danish law, informed consent was not required. The study was deemed a quality-improvement study, and approval from the regional ethics committee was therefore not necessary according to Danish law. ${ }^{31}$

\section{Data Processing}

All patient records were reviewed, and time measurements were assessed. Time to first rhythm analysis/first shock was measured from recorded time of cardiac arrest call at the 
hospital switchboard. Time measures likely to be incorrect (eg, negative time from cardiac arrest call to first rhythm check or defibrillation) were excluded from analysis. Complete data on a patient was defined as having all predefined TTI data available (continuous rhythm, episode duration, compressions per minute and compression rate, no flow time, and -fraction/CCF, number of defibrillations).

Cardiac arrest was assessed by the treating physician and return of spontaneous circulation (ROSC) was defined as adequate circulation for $>20$ minutes in accordance with the Utstein Resuscitation Registry Template for In-Hospital Cardiac Arrest. ${ }^{32}$ We considered pauses in chest compressions as any interruption $>1.5$ seconds according to previous consensus. $^{33}$

All events were analyzed manually at the level of single compressions in accordance with a previous study, ie, the automated annotations were corrected when erroneously placed. ${ }^{34}$ Chest compression rate was defined to be in accordance with guidelines if the mean rate was 100 120 per minute and CCF was defined to be in accordance with guidelines if being $\geq 80 \%{ }^{23,35,36}$

Data from the defibrillators and the patient record were then collected and entered into an encrypted, secure Microsoft Access database (Microsoft, Redmond, WA). Data from the defibrillators and from the hospital records was analyzed and typed into the database first by the study nurse and then by the lead author independently of each other. In case of disagreement, consensus was reached by joint discussion.

\section{Statistical Analysis}

Data was assessed for normality using quantile-quantile plots and histogram analysis. Continuous data is presented as median (quartile 1 - quartile 3 ), and binary data as numbers (percent). The association between survival outcomes and chest compression quality was assessed using multivariate logistic regression with mixed effects and robust standard errors to account for hospital department as a clustering variable. We adjusted for age, Charlson comorbidity index, witnessed status, CPR duration, initial shockable vs non-shockable rhythm, intubation, and use of an AED. Data was analyzed using Stata version 16.0 (StataCorp LP, College Station, TX).

\section{Results}

A total of 335 cardiac arrest calls were made during the study period (Figure 1). In 73 cases the patient was not in cardiac arrest according to the description in the patient record by the cardiac arrest team and 35 cases were excluded

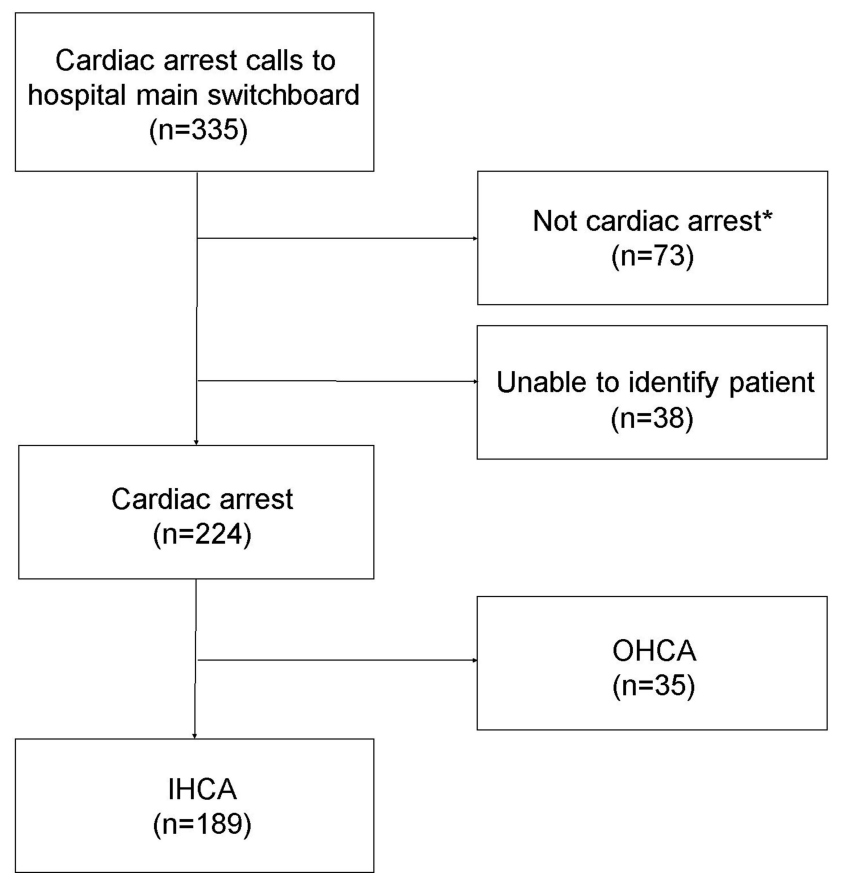

Figure I Flow chart of all cardiac arrest calls. *Not cardiac arrest includes loss of consciousness, seizures, and respiratory failure without cardiac arrest, as evaluated by the treating physicians.

Abbreviations: IHCA, in-hospital cardiac arrest; OHCA, out-of hospital cardiac arrest.

for being OHCA. Overall, 38 cases were excluded because it was impossible to identify the patient's social security number and because the department of anesthesiology had no information about a cardiac arrest call. Accordingly, 189 IHCA were included in this study. Complete TTI data was available on 118 patients $(60 \%)$

Baseline demographics are presented in Table 1. The majority of IHCA-patients were significantly co-morbid (83\% Charlson Cormorbidity Index $\geq 3$ ). The incidence of IHCA was 3.0 per 1,000 admissions (hospital admissions during the study period: 64,039). The majority of IHCAs took place in the Department of Internal Medicine and Department of Cardiology.

CPR quality data is reported in Tables 2 and 3. Overall, chest compression rate was often faster than guideline recommendations and $\mathrm{CCF}$ was slightly below guideline recommendations. Median CCF was higher at $85 \%$ $(\mathrm{IQR}=73-91)$ when a manual defibrillator was used vs a median of $72 \%(\mathrm{IQR}=64-78)$ with AED use.

Median (interquartile range) time to first rhythm analysis was 116 seconds (70-201) and median time to first defibrillation was 133 seconds (82-264).

ROSC was achieved in $53 \%$ of patients with a 30 -day survival of $25 \%$. Survival until 1, 3, and 5 years was $21 \%$, 
Table I Cardiac Arrest Variables

\begin{tabular}{|l|r|}
\hline Number of IHCA & 189 \\
\hline Male (N(\%)) & $123(65)$ \\
\hline Witnessed cardiac arrest (N(\%)) & \\
- Yes & $33(76)$ \\
- No & $37(20)$ \\
- Not documented in patient record & $9(5)$ \\
\hline IHCA time of day (N(\%)) & \\
Day 08.00 AM-03.59 PM & $88(47)$ \\
Evening 04.00 PM-II.59 PM & $49(26)$ \\
Night I2.00 AM-07.59 AM & $52(28)$ \\
\hline Cardiac arrest location (N(\%)) & \\
Internal Medicine Ward & $46(24)$ \\
Cardiology Ward & $42(22)$ \\
Intensive Care Unit & $30(16)$ \\
Surgical Wards & $28(15)$ \\
Emergency Care Unit & $13(7)$ \\
Neurology Ward & $10(5)$ \\
Oncology Ward & $7(4)$ \\
Other* & $13(7)$ \\
\hline
\end{tabular}

Notes: *Other=Psychiatric ward, elevators, main entrance hall, radiation therapy, operating rooms, recovery unit, radiology department.

Abbreviation: IHCA, in-hospital cardiac arrest.

Table 2 Cardiopulmonary Resuscitation Quality Metrics

\begin{tabular}{|l|r|}
\hline $\begin{array}{l}\text { Median cardiac arrest episode } \\
\text { duration per patient }\end{array}$ & 391 (I76-804) sec \\
Median time to first defibrillation & $133(82-264) \mathrm{sec}$ \\
Time to first rhythm analysis & $116(70-201) \mathrm{sec}$ \\
Median chest compressions rate & $126(119-131) \mathrm{min}^{-1}$ \\
Median chest compression fraction & $78(69-86) \%$ \\
\hline
\end{tabular}

Note: All results are presented as median (quartile I - quartile 3).

$14 \%$, and $13 \%$, respectively (Table 4 ). Chest compression rate and $\mathrm{CCF}$ was not significantly associated with better survival outcomes when performed within guideline
Table 4 Cardiac Arrest Survival

\begin{tabular}{|l|r|r|r|r|r|}
\hline & ROSC & $\begin{array}{r}\text { 30-Day } \\
\text { Survival }\end{array}$ & $\begin{array}{r}\text { I-Year } \\
\text { Survival }\end{array}$ & $\begin{array}{r}\text { 3-Year } \\
\text { Survival }\end{array}$ & $\begin{array}{r}\text { 5-Year } \\
\text { Survival }\end{array}$ \\
\hline $\begin{array}{r}\text { Survival } \\
(\mathrm{N}(\%))\end{array}$ & $100(53)$ & $47(25)$ & $40(2 \mathrm{I})$ & $27(14)$ & $25(13)$ \\
\hline
\end{tabular}

Abbreviation: ROSC, return of spontaneous circulation.

recommendations in unadjusted analyses. In adjusted analysis, $\mathrm{CCF}>80 \%$ was not significantly associated with survival outcomes, whereas chest compression rate within guideline recommendation was significantly associated with better survival at 30 days and 3 years. Patients who survived 5 years after cardiac arrest are described in Table 5 and compared to the patients who did not survive for 5 years. Fiveyear survival was associated with younger age, less comorbidity, and witnessed cardiac arrest.

\section{Discussion}

We initiated a systematic collection of CPR quality data from AEDs and manual defibrillators and found a median time to first rhythm check/defibrillation of less than 3 minutes, a chest compression rate that was too fast, and a CCF slightly below $80 \%$. There was an overall shortterm survival comparable to major IHCA registries and more than half of 30-day survivors were still alive at 5 years. Long-term survival was associated with younger age, less comorbidity, and witnessed cardiac arrest. We did not find a significant association between CCF and survival outcomes, but we did find a significant association between chest compression rates and survival to 30 days and 3 years.

\section{CPR Quality}

Data on CPR quality for adult IHCA is limited and existing studies include 60-222 patients, making the current study

Table 3 Chest Compression Rate and Fraction

\begin{tabular}{|l|r|r|r|r|r|}
\hline & ROSC & $\begin{array}{r}\text { 30-Day } \\
\text { Survival }\end{array}$ & $\begin{array}{r}\text { I-Year } \\
\text { Survival }\end{array}$ & $\begin{array}{r}\text { 3-Year } \\
\text { Survival }\end{array}$ & $\begin{array}{r}5-Y e a r \\
\text { Survival }\end{array}$ \\
\hline $\begin{array}{l}\text { Chest Compression rate 100-120 per minute } \\
\text { - Unadjusted OR [95\% Cl] }\end{array}$ & $0.55[0.25-1.19]$ & $1.01[0.42-2.43]$ & $1.05[0.42-2.64]$ & $1.14[0.40-3.26]$ & $0.93[0.29-2.90]$ \\
- Adjusted* OR [95\% Cl] & $0.60[0.31-1.17]$ & $2.04[1.30-3.18]$ & $1.67[0.80-3.47]$ & $2.50[1.23-5.08]$ & $1.65[0.73-3.70]$ \\
\hline $\begin{array}{l}\text { Chest Compression Fraction CCF >80\% } \\
\text { - Unadjusted OR [95\% Cl] }\end{array}$ & $0.77[0.37-1.60]$ & $0.18[0.06-0.57]$ & $0.21[0.07-0.66]$ & $0.32[0.08-1.25]$ & $0.42[0.11-1.67]$ \\
- Adjusted* OR [95\% Cl] & $0.46[0.07-2.98]$ & $0.22[0.04-1.11]$ & $0.40[0.05-2.96]$ & $0.82[0.21-3.15]$ & $0.79[0.21-2.95]$ \\
\hline
\end{tabular}

Notes: Odds ratio unadjusted and adjusted (*) for age, first rhythm, intubation, use of automated external defibrillator, Charlson comorbidity Index, witnessed cardiac arrest, and episode duration. 
Table 5 Comparison of Patients with 5-Year Survival vs No 5-Year Survival

\begin{tabular}{|c|c|c|c|}
\hline & 5-Year Survival & No 5-Year Survival & $p$-value \\
\hline Total, N (\%) & $25(13)$ & $164(87)$ & \\
\hline Age in years (median (QI-Q3)) & $68(59-73)$ & $74(66-84)$ & 0.003 \\
\hline Male (N (\%)) & $17(68)$ & $106(65)$ & 0.74 \\
\hline Cardiac arrests in telemetry equipped wards (N (\%)) & II (44) & $61(37)$ & \\
\hline Charlson comorbidity index (median (QI-Q3)) & $3(2-4)$ & $5(3-6)$ & $<0.001$ \\
\hline Witnessed cardiac arrest of patients with recorded data $(\mathrm{N}(\%))$ & $23(96)^{*}$ & $120(77)^{*}$ & 0.03 \\
\hline First rhythm: Shockable $(\mathrm{N}(\%))$ & $8(44)^{*}$ & $17(15)^{*}$ & \\
\hline Time to first shock in sec (median (QI-Q3)) & $133(73-17 \mid)$ & $138(83-293)$ & 0.71 \\
\hline Time to first rhythm analysis in sec (median (QI-Q3)) & $238(104-382)$ & $110(69-185)$ & 0.05 \\
\hline Episode duration sec (median (QI-Q3)) & I44 (72-270) & $415(206-855)$ & 0.002 \\
\hline Chest compression fraction (\% (QI-Q3)) & $73(68-80)$ & $78(69-86)$ & 0.52 \\
\hline Compression rate per minute during compressions (median (QI-Q3)) & $125(119-134)$ & $126(\mid 19-131)$ & 0.88 \\
\hline
\end{tabular}

Notes: $\mathrm{Q} I=25 \%$ percentile. $\mathrm{Q} 3=75 \%$ percentile. *Fraction is shown as percent of patients with available data on this parameter.

the second largest study. ${ }^{12-15}$ We found a median time from cardiac arrest call to first rhythm analysis/first defibrillation was about 2 minutes, which is within the 3 minutes recommended in current guidelines. ${ }^{23,35}$ Our data is in line with the Danish IHCA registry showing a median time to first rhythm analysis of 2 minutes. ${ }^{5}$ Notably, our time estimates are from a hospital with AEDs distributed on wards without a manual defibrillator, and more than $25 \%$ of events still had delays in time to first rhythm check and/or first shock. Thus, our data suggests that increased focus on implementation and training on early defibrillation is essential to reduce time to first shock in the hospital.

Current guideline recommendations on high-quality chest compressions with short pauses are primarily based on data from out-of-hospital cardiac arrest. ${ }^{23,35}$ In our study, the median chest compression rate was above the recommended 100 120 compressions per minute, which is higher compared to studies by Abella et $\mathrm{al}^{12,13}$ that were conducted when guidelines recommended a rate of approximately 100 per minute. However, the rates in our study are slightly lower compared to a more recent study showing a mean rate of 139/min for IHCA. ${ }^{14}$ Notably, we did not utilize audio-visual feedback on CPR quality or CPR coaching during resuscitation, which is associated with improved guideline adherence. ${ }^{24,37}$

Guidelines recommending a compression rate at 100 $120 / \mathrm{min}^{21,23}$ are based on out-of-hospital cardiac arrest studies showing that this range of compression rate is associated with better survival outcomes. ${ }^{9,38}$ This is the first study on IHCA showing an association between guideline-adherent chest compression rates and survival to 30 days and 1 year. ${ }^{11}$ Only one previous study has investigated the association between chest compression rates and survival outcomes, showing that a rate $>120$ / min was associated with better outcomes, which may be due to a higher chest compression rate resulting in higher coronary perfusion pressure. ${ }^{14}$ Notably, all of our point estimates suggest better survival outcomes for chest compression rates at $100-120 / \mathrm{min}$, although we did not find significant associations for 1-year survival and 5-year survival. This is likely due to a type 2 error.

Our finding of a median CCF of $78 \%$ is in line with previous findings from Abella et $\mathrm{al}^{12,13}$ showing a CCF of $76 \%$, and slightly lower than the recommendation of $\geq 80 \%$ by the American Heart Association. ${ }^{39}$ However, data on the association between CCF and survival outcomes is diverging, and many studies show an inverse trend between $\mathrm{CCF}$ and survival in line with our findings. ${ }^{8,40-42}$ Thus, CCF may not be the most important metric to guide in-hospital resuscitation quality improvement measures.

\section{Survival Data}

Short-term survival rate in our study at 30 days was comparable to reported survival in both international and Nordic registries. ${ }^{1-5}$ One-year survival in Denmark has previously been reported at $22 \%$ in a nationwide registry comparable to our findings. ${ }^{5}$ Only one study has reported 3 -year IHCA survival ${ }^{22}$ and, to our knowledge, this is the first study to report 5-year survival following IHCA.

In our study, survival decreased from year 1 to year 3, but remained stable from year 3 to year 5 . In a previous study on long-term survival among elderly patients in the US, $43.5 \%$ of those surviving to hospital discharge were still alive at 3 years. ${ }^{22}$ In our study, $57 \%$ of 30 -day survivors were still alive at 3 years. The difference in 3 -year 
survival rate may be explained by the higher proportion of elderly patients in the other study. Importantly, our data show no significant decline in survival from 3 -years to 5 years. It remains unknown whether this finding reflects that those patients surviving to 3-years generally have favorable neurological outcomes, as we do not have data on neurological outcomes in this study. Importantly, data from Sweden with a comparable population and healthcare system and similar survival rates show that most patients surviving to hospital discharge have favorable neurological outcomes. ${ }^{43}$

Patients who survived 5 years after cardiac arrest were younger with less comorbidity, included more witnessed cardiac arrests, a shorter CPR duration, and more shockable rhythms when compared to non-survivors. These findings are all in line with other studies showing that these factors are associated with improved survival. $1,22,23,35,44$

\section{Objective and Complete Data Collection and Implementation}

Obtaining accurate and reliable data on cardiac arrest treatment is a challenge as many parameters are based on the treating clinician's subjective registration leading to inaccurate data. ${ }^{45-47}$ We used TTI data from defibrillators that offer more objective data relating to, eg, time annotations, defibrillation, and chest compressions. However, important time points such as time to first compression and cardiac arrest team response time may still not be available using defibrillator data. We did not have complete data on all cardiac arrests, which is known from previous studies on OHCA reporting complete data on $69 \%$ and $67 \%$ of cardiac arrests using TTI. ${ }^{27,34}$ Using multiple sources of information on cardiac arrests, such as video data, accelerometers, GPS locators, apps, and data from the patient journal, may increase data completeness. ${ }^{13,48}$ Furthermore, we do not have data on, eg, chest compression depth, as we do not have accelerometer data. The advantage of TTI is the opportunity of readily collecting data from existing defibrillators as compared to accelerometers that may require both new equipment and computer software. Thus, it is fairly easy to implement and may be a cost-effective method for hospitals to study CPR quality metrics.

\section{Perspectives}

The information we collected on the quality of cardiac arrest treatment in this study was disseminated to the doctors and nurses in our institution via mandatory basic and advanced life support courses. Thus, we utilized the data from resuscitations to emphasize early rhythm check and defibrillation, short chest compression interruptions, and proper chest compression rate. We also informed the staff of our hospital short-term survival rates and response times.

\section{Limitations}

This study has several limitations. This is a single center study. Due to a large degree of homogeneity in the Danish healthcare system, our findings are likely to apply to other Danish hospitals $^{49}$ and similar healthcare systems. We did not synchronize all clocks in the hospital prior to commencing our study, and unsynchronized clocks is a major limiting factor in achieving exact time annotations in cardiac arrest registries. ${ }^{47,50-52}$ Moreover, we did not have complete data in line with other studies. ${ }^{4,50-52}$ Due to the number of cardiac arrests in our study we cannot with certainty infer an association between CPR quality and survival outcomes. Furthermore, we do not have any information on chest compression depth and neurological outcomes. ${ }^{11,53}$

\section{Conclusions}

We established a systematic collection of CPR quality data from IHCA to measure and improve CPR quality and longterm survival outcomes. Median time to first rhythm check/ defibrillation was $<3$ minutes but median chest compression rate was too fast and median CCF slightly below $80 \%$. More than half of 30-day survivors were still alive at 5 years.

\section{Funding}

This work was funded by The South Denmark Region Research Foundation (grant number 13/6968), The HedeNielsen Foundation and The Development Council and The Chief Physicians Council, Lillebaelt Hospital, Vejle. The funding sources had no influence on the conduct of the research, the preparation of the article, the collection, analysis, and interpretation of data, or in the writing of the article.

\section{Disclosure}

The authors report no conflicts of interest in this work.

\section{References}

1. Sandroni C, Nolan J, Cavallaro F, Antonelli M. In-hospital cardiac arrest: incidence, prognosis and possible measures to improve survival. Intensive Care Med. 2007;33(2):237-245. doi:10.1007/s00134-0060326-z

2. Holmberg MJ, Ross CE, Fitzmaurice GM, et al. Annual incidence of adult and pediatric in-hospital cardiac arrest in the United States. Circ Cardiovasc Qual Outcomes. 2019;12(7):e005580. doi:10.1161/ CIRCOUTCOMES.119.005580 
3. Andersen LW, Holmberg MJ, Berg KM, Donnino MW, Granfeldt A. In-hospital cardiac arrest: a review. JAMA. 2019;321(12):1200-1210. doi:10.1001/jama.2019.1696

4. Hjärt-Lungräddningsregistret S. Årsrapport 2019 Svenska HjärtLungräddningsregistret. Svenska Hjärt-Lungräddningsregistret. [Annual report from the Swedish cardiac arrest registry]. Available from: https://www.hlr.nu/wp-content/uploads/2019/11/\%C3\%85rsrap port-Svenska-Hj\%C3\%A4rt-Lungr\%C3\%A4ddningsregistret-2019_ reduced.pdf. Accessed October 15, 2020.

5. (RKKP) RKK. DANARREST årsrapport 2019. Danske Regioner. [Annual report from the Danish IHCA registry]. Available from: https:// www.sundhed.dk/content/cms/83/70283_danarrest_aarsrapport2019_ 20200625endelig.pdf. Accessed October 14, 2020.

6. Chan PS, Krumholz HM, Nichol G, Nallamothu BK; Investigators AHANRoCR. Delayed time to defibrillation after in-hospital cardiac arrest. $N$ Engl J Med. 2008;358(1):9-17. doi:10.1056/NEJMoa0706467

7. Chan PS, Nichol G, Krumholz HM, Spertus JA, Nallamothu BK; Investigators AHANRoCRN. Hospital variation in time to defibrillation after in-hospital cardiac arrest. Arch Intern Med. 2009;169 (14):1265-1273. doi:10.1001/archinternmed.2009.196

8. Brouwer TF, Walker RG, Chapman FW, Koster RW. Association between chest compression interruptions and clinical outcomes of ventricular fibrillation out-of-hospital cardiac arrest. Circulation. 2015;132 (11):1030-1037. doi:10.1161/CIRCULATIONAHA.115.014016

9. Idris AH, Guffey D, Aufderheide TP, et al. Relationship between chest compression rates and outcomes from cardiac arrest. Circulation. 2012;125(24):3004-3012. doi:10.1161/ CIRCULATIONAHA.111.059535

10. Cheskes S, Schmicker RH, Rea T, et al. The association between AHA CPR quality guideline compliance and clinical outcomes from out-of-hospital cardiac arrest. Resuscitation. 2017;116:39-45. doi:10.1016/j.resuscitation.2017.05.003

11. Considine J, Gazmuri RJ, Perkins GD, et al. Chest compression components (rate, depth, chest wall recoil and leaning): a scoping review. Resuscitation. 2020;146:188-202. doi:10.1016/j. resuscitation.2019.08.042

12. Abella BS, Sandbo N, Vassilatos P, et al. Chest compression rates during cardiopulmonary resuscitation are suboptimal: a prospective study during in-hospital cardiac arrest. Circulation. 2005;111 (4):428-434. doi:10.1161/01.CIR.0000153811.84257.59

13. Abella BS, Alvarado JP, Myklebust H, et al. Quality of cardiopulmonary resuscitation during in-hospital cardiac arrest. JAMA. 2005;293(3):305-310. doi:10.1001/jama.293.3.305

14. Kilgannon JH, Kirchhoff M, Pierce L, Aunchman N, Trzeciak S, Roberts BW. Association between chest compression rates and clinical outcomes following in-hospital cardiac arrest at an academic tertiary hospital. Resuscitation. 2017;110:154-161. doi:10.1016/j. resuscitation.2016.09.015

15. Edelson DP, Abella BS, Kramer-Johansen J, et al. Effects of compression depth and pre-shock pauses predict defibrillation failure during cardiac arrest. Resuscitation. 2006;71(2):137-145. doi:10. 1016/j.resuscitation.2006.04.008

16. Edelson DP, Litzinger B, Arora V, et al. Improving in-hospital cardiac arrest process and outcomes with performance debriefing. Arch Intern Med. 2008;168(10):1063-1069. doi:10.1001/archinte.168.10.1063

17. Wolfe H, Zebuhr C, Topjian AA, et al. Interdisciplinary ICU cardiac arrest debriefing improves survival outcomes*. Crit Care Med. 2014;42 (7):1688-1695. doi:10.1097/CCM.0000000000000327

18. Greif R, Lockey A, Breckwoldt J, et al. European Resuscitation Council Guidelines 2021: education for resuscitation. Resuscitation. 2021;161:388-407. doi:10.1016/j.resuscitation.2021.02.016

19. Cheng A, Magid DJ, Auerbach M, et al. Part 6: resuscitation education science: 2020 American Heart Association Guidelines for Cardiopulmonary Resuscitation and Emergency Cardiovascular Care. Circulation. 2020;142(16 suppl 2):S551-S579. doi:10.1161/ CIR.0000000000000903
20. Greif R, Bhanji F, Bigham BL, et al. Education, Implementation, and Teams: 2020 International Consensus on Cardiopulmonary Resuscitation and Emergency Cardiovascular Care Science with treatment recommendations. Circulation. 2020;142(16_suppl_1): S222-S283. doi:10.1161/CIR.0000000000000896

21. Perkins GD, Graesner JT, Semeraro F, et al. European resuscitation council guidelines 2021: executive summary. Resuscitation. 2021;161:1-60. doi:10.1016/j.resuscitation.2021.02.003

22. Chan PS, Spertus JA, Nallamothu BK. Long-term outcomes in elderly survivors of cardiac arrest. $N$ Engl J Med. 2013;368 (25):2438-2439. doi:10.1056/NEJMc1305198

23. Panchal AR, Bartos JA, Cabañas JG, et al. Part 3: adult basic and advanced life support: 2020 American Heart Association Guidelines for Cardiopulmonary Resuscitation and Emergency Cardiovascular Care. Circulation. 2020;142(16_suppl_2):S366-S468. doi:10.1161/ CIR.0000000000000916

24. Nolan JP, Maconochie I, Soar J, et al. Executive summary: 2020 International Consensus on Cardiopulmonary Resuscitation and Emergency Cardiovascular Care Science with treatment recommendations. Circulation. 2020;142(16_suppl_1):S2-S27. doi:10.1161/CIR.0000000000000890

25. Alonso E, Ruiz J, Aramendi E, et al. Reliability and accuracy of the thoracic impedance signal for measuring cardiopulmonary resuscitation quality metrics. Resuscitation. 2015;88:28-34. doi:10.1016/j. resuscitation.2014.11.027

26. Ayala U, Eftestol T, Alonso E, et al. Automatic detection of chest compressions for the assessment of CPR-quality parameters. Resuscitation. 2014;85(7):957-963. doi:10.1016/j. resuscitation.2014.04.007

27. Stecher FS, Olsen JA, Stickney RE, Wik L. Transthoracic impedance used to evaluate performance of cardiopulmonary resuscitation during out of hospital cardiac arrest. Resuscitation. 2008;79(3):432-437. doi:10.1016/j.resuscitation.2008.08.007

28. Hunt EA, Jeffers J, McNamara L, et al. Improved cardiopulmonary resuscitation performance with $\operatorname{CODE} \operatorname{ACES}(2)$ : a resuscitation quality bundle. J Am Heart Assoc. 2018;7(24):e009860. doi:10.1161/ JAHA.118.009860

29. Statistik D. Danmarks Statistik - Folketal. Danmarks Statistik. [Statistics Denmark - population figures]. Available from: https://www.statistikban $\mathrm{ken} . \mathrm{dk} /$ statbank5a/selectvarval/define.asp? PLanguage $=0 \&$ subword $=$ tabsel\&MainTable $=$ FOLK1 A\&PXSId $=199114 \&$ tablestyle $=\& S T=$ SD\&buttons $=0$. Accessed October 14, 2020.

30. Kvalitetsudviklingsprogram RK. [Danish Anesthesia Database]. Available from: https://www.rkkp.dk/kvalitetsdatabaser/databaser/danskanaestesi-database/. Accessed December 21, 2021.

31. Sundhedsstyrelsen. Vejledning om indførelse af nye behandlinger i sundhedsvæsenet. [Danish Health Authority. Guidance on the implementation of new treatments in the health care system]. Available from: https://www.retsinformation.dk/eli/retsinfo/1999/ 11052. Accessed October 25, 2020.

32. Nolan JP, Berg RA, Andersen LW, et al. Cardiac Arrest and Cardiopulmonary Resuscitation Outcome Reports: update of the Utstein Resuscitation Registry Template for In-Hospital Cardiac Arrest: a Consensus Report From a Task Force of the International Liaison Committee on Resuscitation (American Heart Association, European Resuscitation Council, Australian and New Zealand Council on Resuscitation, Heart and Stroke Foundation of Canada, InterAmerican Heart Foundation, Resuscitation Council of Southern Africa, Resuscitation Council of Asia). Resuscitation. 2019. doi:10.1016/j. resuscitation.2019.08.021

33. Kramer-Johansen J, Edelson DP, Losert H, Kohler K, Abella BS. Uniform reporting of measured quality of cardiopulmonary resuscitation (CPR). Resuscitation. 2007;74(3):406-417. doi:10.1016/j. resuscitation.2007.01.024 
34. Krarup NH, Terkelsen CJ, Johnsen SP, et al. Quality of cardiopulmonary resuscitation in out-of-hospital cardiac arrest is hampered by interruptions in chest compressions-a nationwide prospective feasibility study. Resuscitation. 2011;82(3):263-269. doi:10.1016/j. resuscitation.2010.11.003

35. Olasveengen TM, Semeraro F, Ristagno G, et al. European resuscitation council guidelines 2021: basic life support. Resuscitation. 2021;161:98-114. doi:10.1016/j.resuscitation.2021.02.009

36. Olasveengen TM, Mancini ME, Perkins GD, et al. Adult basic life support: 2020 International Consensus on Cardiopulmonary Resuscitation and Emergency Cardiovascular Care Science with treatment recommendations. Circulation. 2020;142(16_suppl_1): S41-S91. doi:10.1161/CIR.0000000000000892

37. Cheng A, Duff JP, Kessler D, et al. Optimizing CPR performance with CPR coaching for pediatric cardiac arrest: a randomized simulation-based clinical trial. Resuscitation. 2018;132:33-40. doi:10.1016/j.resuscitation.2018.08.021

38. Idris AH, Guffey D, Pepe PE, et al. Chest compression rates and survival following out-of-hospital cardiac arrest. Crit Care Med. 2015;43(4):840-848. doi:10.1097/CCM.00000000000 00824

39. Meaney PA, Bobrow BJ, Mancini ME, et al. Cardiopulmonary resuscitation quality: [corrected] improving cardiac resuscitation outcomes both inside and outside the hospital: a consensus statement from the American Heart Association. Circulation. 2013;128(4):417-435. doi:10.1161/CIR.0b013e31829d8654

40. Wik L, Olsen JA, Persse D, et al. Why do some studies find that CPR fraction is not a predictor of survival? Resuscitation. 2016;104:59-62. doi:10.1016/j.resuscitation.2016.04.013

41. Vaillancourt C, Petersen A, Meier EN, et al. The impact of increased chest compression fraction on survival for out-ofhospital cardiac arrest patients with a non-shockable initial rhythm. Resuscitation. 2020;154:93-100. doi:10.1016/j. resuscitation.2020.06.016

42. Talikowska M, Tohira H, Inoue M, Bailey P, Brink D, Finn J. Lower chest compression fraction among patients with longer downtime and ROSC was not due to peri-shock pause. Resuscitation. 2017;119:e17-e18. doi:10.1016/j.resuscitation.2017. 08.002

43. Al-Dury N, Rawshani A, Israelsson J, et al. Characteristics and outcome among 14,933 adult cases of in-hospital cardiac arrest: a nationwide study with the emphasis on gender and age. Am J Emerg Med. 2017;35 (12):1839-1844. doi:10.1016/j.ajem.2017.06.012
44. Piscator E, Hedberg P, Göransson K, Djärv T. Survival after in-hospital cardiac arrest is highly associated with the Age-combined Charlson Co-morbidity Index in a cohort study from a two-site Swedish University hospital. Resuscitation. 2016;99:79-83. doi:10.1016/j.resuscitation.2015.11.023

45. Grundgeiger T, Albert M, Reinhardt D, Happel O, Steinisch A, Wurmb T. Real-time tablet-based resuscitation documentation by the team leader: evaluating documentation quality and clinical performance. Scand J Trauma Resusc Emerg Med. 2016;24:51. doi:10.1186/s13049-016-0242-3

46. Peace JM, Yuen TC, Borak MH, Edelson DP. Tablet-based cardiac arrest documentation: a pilot study. Resuscitation. 2014;85 (2):266-269. doi:10.1016/j.resuscitation.2013.10.013

47. Kaye W, Mancini ME, Truitt TL. When minutes count-the fallacy of accurate time documentation during in-hospital resuscitation. Resuscitation. 2005;65(3):285-290. doi:10.1016/j.resuscitation.20 04.12.020

48. Andrew Lockey IB, Mackie K, Yeung J, et al.. UK resuscitation guidelines 2021. EducationGuidelines. Available from: https:/www. resus.org.uk/library/2021-resuscitation-guidelines/education-guide lines. Accessed December 12, 2021. .

49. Henriksen DP, Rasmussen L, Hansen MR, Hallas J, Pottegård A. Comparison of the five Danish regions regarding demographic characteristics, healthcare utilization, and medication use-a descriptive cross-sectional study. PLoS One. 2015;10(10):e0140197. doi:10.13 71/journal.pone.0140197

50. Jones PG, Miles JL. Overcoming barriers to in-hospital cardiac arrest documentation. Resuscitation. 2008;76(3):369-375. doi:10.1016/j. resuscitation.2007.08.021

51. Cordell WH, Olinger ML, Kozak PA, Nyhuis AW. Does anybody really know what time it is? Does anybody really care? Ann Emerg Med. 1994;23(5):1032-1036. doi:10.1016/s0196-0644(94)70099-0

52. Ornato JP, Doctor ML, Harbour LF, et al. Synchronization of timepieces to the atomic clock in an urban emergency medical services system. Ann Emerg Med. 1998;31(4):483-487. doi:10.1016/S01960644(98)70258-6

53. Nielsen N, Wetterslev J, Cronberg T, et al. Targeted temperature management at $33^{\circ} \mathrm{C}$ versus $36^{\circ} \mathrm{C}$ after cardiac arrest. $N$ Engl $J$ Med. 2013;369(23):2197-2206. doi:10.1056/NEJMoa1310519

\section{Publish your work in this journal}

The Open Access Emergency Medicine is an international, peerreviewed, open access journal publishing original research, reports, editorials, reviews and commentaries on all aspects of emergency medicine. The manuscript management system is completely online and includes a very quick and fair peer-review system, which is all easy to use. Visit http://www.dovepress.com/testimonials.php to read real quotes from published authors. 